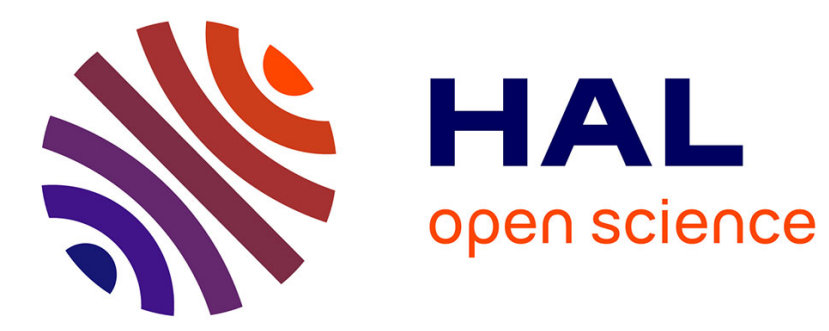

\title{
Somebody may scold you! A dictator experiment
}

Agnès Festré, Pierre Garrouste

\section{To cite this version:}

Agnès Festré, Pierre Garrouste. Somebody may scold you! A dictator experiment. Journal of Economic Psychology, 2014, 45, pp.141-153. 10.1016/j.joep.2014.09.005 . hal-01069807

\section{HAL Id: hal-01069807 https://hal.science/hal-01069807}

Submitted on 29 Sep 2014

HAL is a multi-disciplinary open access archive for the deposit and dissemination of scientific research documents, whether they are published or not. The documents may come from teaching and research institutions in France or abroad, or from public or private research centers.
L'archive ouverte pluridisciplinaire HAL, est destinée au dépôt et à la diffusion de documents scientifiques de niveau recherche, publiés ou non, émanant des établissements d'enseignement et de recherche français ou étrangers, des laboratoires publics ou privés. 
Elsevier Editorial System(tm) for Journal of Economic Psychology Manuscript Draft

Manuscript Number: JOEP-D-14-00037R2

Title: Somebody may scold you! A dictator experiment

Article Type: Research Paper

Corresponding Author: Prof. Agnès Festré,

Corresponding Author's Institution: University of Picardie Jules Verne

First Author: Agnès Festré, Professor

Order of Authors: Agnès Festré, Professor

Abstract: In this contribution, we investigate the effects of observation-only and observation with feedback from a third-party, in a one-shot dictator game (DG). In addition to a baseline condition (DG), a third-party anonymous subject is introduced who either silently observes or observes and gives feedback by choosing one of seven messages consisting of varying degrees of (dis)satisfaction. We found that observation coupled with feedback significantly increases dictators' propositions, while no significant effect is found for observation-only. We conclude that regard by others matters only if it is linked to social factors such as communication. This complements the literature that argues that altruistic behavior is instrumental in serving other selfish (or non-purely altruistic) ends such as selfreputation or social approval. This experiment contributes to the growing literature aimed at decreasing the artificiality of DG designs, by increasing their practicability and external validity. 
Nice August 6, 2014

Dear Prof Doctor Carlos Alos-Ferrer

Please find attached the revised version of our submission to the Journal of Economic

Psychology titled "Somebody may scold you! A dictator experiment" with references JOEP-

D-14-00037

Looking forward to hearing from you

All the best

Agnès Festré 


\section{ANSWERS TO REVIEWERS AND REVISIONS}

\section{Answers to REVIEWER 1}

Some elements concerning possible theoretical foundations of social disapproval have been introduced in the introduction.

Xiao and Houser (2009) is indeed an important existing reference, which has been added in the list of references. Actually, it was already included and cited in its WP version as Xiao, E. \& Houser, D. (2007).Emotion expression and fairness in economic exchange, Discussion Paper, Interdisciplinary Center for Economic Science (ICES), George Mason University. http://repec.ices-gmu.org/RePEc/pdf/1004.pdf.

\section{Answers to REVIEWER 2 following the structure of the review}

\section{MAJOR COMMENTS}

\subsection{Theoretical arguments}

Concerning the analogy with the impartial spectator of Adam Smith's Theory of Moral $\underline{\text { Sentiments }}$

Answer to the reviewer: We agree that it is a concept that is more related to moral norms than to social norms (such as fairness as in our case). However, we consider that the analogy is relevant since what our results show is that individuals modify their behavior only by anticipating the feedback of the third-party (remember it is a one-shot game). There is no need of social interactions as in the case of the impartial spectator.

Concerning the difference between social distance and anonymity

Footnote 3 has been amended in order to stress the difference between social distance and anonymity. Part of former footnote 3 (i.e., the part mentioning only references that are more directly linked to our work) has been converted to plain text. The list of references referring to well-known developments on social preferences has been dropped (Sobel 2007, Charness and Rabin 2005, Fehr and Schmidt 1999, Bolton and Ockenfels 2000, Andreoni and Miller, 2002).

Concerning the socialization effect

Answer to the reviewer:

We did not insist on the theoretical foundation of the "socialization effect" since we found no effect of modifying the sequence "attribution of roles then matching within groups or the other way around". Furthermore the term is somewhat misleading. We in fact simply refer to the idea of an order effect that may reduce the social distance between subjects belonging to the same group.

Footnote 9 (former footnote 6 ) has been therefore revised by adding the references suggested by the reviewer (Luhan et al. 2009, Franzen and Pointer 2013) that show contrasting results as regard to the existence of a socialization effect in group dictator games. 


\subsection{Experimental design and participants}

\subsection{Reporting of results}

The 66 observations of the post-play intentions do not correspond to specific treatments but are linked with the observation with feedback ones. Accordingly we have $66 \times 2=132$ subjects for the control treatments, $66 \times 3 \times 2=198$ for the observation only treatments and $66 \times 3 \times 2=198$ for the observation with feedback treatments. That means that 528 subjects have been concerned by our experiments. F' corresponds to what the subjects would have been given if they would to play again. Accordingly the design is a between one but for those sessions.

We add t-tests in appendix $\mathrm{C}$. The differences between treatments $\mathrm{O}$ and $\mathrm{F}$ and $\mathrm{C}$ and $\mathrm{F}$ are statistically significant.

As for table 1, the percentages are adjusted (1 subject corresponds to an exact percentage of 1.51515151515152). 15 subjects gave 3 in the observation only treatment. The exact percentage is then 22.7272727272727 . We have adjusted it to $22.73 \%$.

As for the treatment $\mathrm{C}$, thank you, you are right; the values were not correctly reported. Accordingly table 1 has been modified. Our results however do not changed because they are calculated with the right values. The fact that $33.33 \%$ of the subjects given half or more of their endowment is in line with Andreoni and Bernheim (2009).

We agree with the fact that the averages of the gifts in the control and observation only treatments are equal up to the $6^{\text {th }}$ position after the decimal point has an almost nil probability to appear. It is however the case.

We changed the regression according to your advice.

\section{Minor comments}

- P. 3/4: The reference to Mohlin and Johannesson (208) has been dropped since it is an example for the reduction of social distance as communication is introduced ex ante.

- Footnote 7 (p. 10) now footnote 9 (p. 10) has been reworded for clarity. By 'very fast' formation, we mean that subjects are passive (they read on the computer that they are going to be matched with two others) and have not the time to realize (due to the speed of the flow information they are subject to) that have been grouped.

- $\quad$ Figure 2/figure 3 has been standardized

- p. 12. The cross-reference has been revised. It refers to footnote 6 instead of footnote 1.

- We removed a figure ( the histograms of the results) and an appendix

- Figure 5 that becomes figure 4 has been changed according to your advice.

- We have changed the regression (we ran a tobit one) and put the SD in parentheses

- The typo error (Johanensson instead of Johannesson) has been corrected 



\section{Highlights}

- we study the role of observation and sanction on individual behavior

- observation is provided by introducing a third-party in a dictator game

- sanction is provided by means of a written feedback from the receiver in a dictator game

- we show that observation alone has no effect on behavior

- observation with feedback increases the generosity of dictators 


\title{
Somebody may scold you! A dictator experiment
}

\author{
Agnès Festré, CRIISEA, University of Picardie Jules Verne \\ Postal address: CRIISEA, Pôle Cathédrale, 10 Placette Lafleur, BP 2716, 80027 Amiens \\ Cedex (France). \\ E-mail address: festre@gredeg.cnrs.fr. Phone number: 0033493954367. \\ Corresponding author \\ and
}

Pierre Garrouste, GREDEG (UMR n $\left.{ }^{\circ} 7321\right)$, University of Nice - Sophia Antipolis

Postal address: GREDEG, 250 rue Albert Einstein, 06560 Valbonne, Cedex (France).

E-mail address: pierre.garrouste@gredeg.cnrs.fr. Phone number: 0033493954367

\begin{abstract}
In this contribution, we investigate the effects of observation-only and observation with feedback from a third-party in a one-shot dictator game (DG). In addition to a baseline condition (DG), a third-party anonymous subject was introduced who either silently observed or observed and got to give feedback by choosing one of seven messages consisting of varying degree of (dis)satisfaction. We found that observation coupled with feedback increased significantly dictators' propositions, while no significant effect is found for observation-only. We conclude that regard by others matters only if it linked to social factors such as communication. This complements the literature arguing that altruistic behavior is instrumental in serving other selfish (or non-purely altruistic) ends such as self-reputation or social approval. This experiment also contributes to the growing literature that aims at decreasing the artificiality of dictator game designs by increasing their practicability and external validity.
\end{abstract}

JEL Classification codes: C72; C91; D03

PsycINFO Classification codes: $3020 ; 3040$ 
Keywords: social psychology; game theory; communication; beliefs; observation; altruistic behavior 


\title{
Somebody may scold you! A dictator experiment
}

\begin{abstract}
In this contribution, we investigate the effects of observation-only and observation with feedback from a third-party, in a one-shot dictator game (DG). In addition to a baseline condition (DG), a third-party anonymous subject is introduced who either silently observes or observes and gives feedback by choosing one of seven messages consisting of varying degrees of (dis)satisfaction. We found that observation coupled with feedback significantly increases dictators' propositions, while no significant effect is found for observation-only. We conclude that regard by others matters only if it is linked to social factors such as communication. This complements the literature that argues that altruistic behavior is instrumental in serving other selfish (or non-purely altruistic) ends such as self-reputation or social approval. This experiment contributes to the growing literature aimed at decreasing the artificiality of DG designs, by increasing their practicability and external validity.
\end{abstract}

JEL Classification codes: C72; C91; D03

PsycINFO Classification codes: 3020; 3040

Keywords: social psychology; game theory; communication; beliefs; observation; altruistic behavior

\section{Introduction}


As early as 1759 Adam Smith, in the Theory of Moral Sentiments, emphasized the social approbation and disapprobation dimensions of individual behavior: "we are pleased to think that we have rendered ourselves the natural objects of approbation (...) and we are mortified to reflect that we have just merited the blame of those we live with." (Smith, 1976 [1759], p. 116). Moreover, he pointed out that this dimension is intrinsically intertwined with a related self-image notion, i.e., self-approbation or self-esteem: "[w]e endeavour to examine our own conduct as we imagine any other fair and impartial spectator would examine it. If, upon placing ourselves into his [the impartial spectator's] situation, we thoroughly enter into all the passions and motives which influenced it, we approve of it, by sympathy with the approbation of this supposed equitable judge. If otherwise, we enter into his disapprobation, and condemn it." (Ibid, p. 110). Smith also emphasized that conscious feelings such as praise or blame, play a key role in the process of approbation or disapprobation of the conduct of others, and in turn, our self-approbation or self-disapprobation ${ }^{1}$.

A related idea emerges in social psychology in the work by Cooley (1902) who coined the phrase 'looking-glass self', meaning that a person's self grows out of society's interpersonal interactions and the perceptions of others. The term refers to people shaping themselves based on other people's perceptions, which leads to a reinforcement of other people's perspectives on themselves. Recently, this notion was formalized by Bénabou and Tirole (2003) among others, using a principal-agent framework, and analyzing the consequences of such a 'looking-glass self' effect in terms of $\operatorname{costs}^{2}$. The motive of social approbation has also been proposed by economists who do not consider that emotions such as shame or guilt which play a highly complementary role in maintaining one's commitments, can be reduced to costs to be avoided. For Elster (1999, 281-3), shame is defined in terms of the 'action tendencies' it is

\footnotetext{
${ }^{1}$ We agree with one reviewer that the impartial spectator is a concept that is related more to moral norms of the kind discussed by Immanuel Kant (moral imperative) than to social norms such as fairness, which are considered in our experiment.

${ }^{2}$ This approach is in line with Becker (1996).
} 
like to produce, and involves a commitment to certain principles, standards, or norms. This echoes references in the psychological literature to anticipatory shame (see Tracy et al. 2007). In a nutshell, anticipatory shame (in contrast to exposed shamed) is felt by the actor, in the absence of exposure, by imagining how he (or she) would feel were his (or her) normative transgression exposed. Our results are consistent with the idea that anticipatory shame plays a crucial role in shaping behaviour in a dictator game (DG) experiment.

In order to test for the role of social approval on altruistic behavior, we try to disentangle the intertwining influences of observation-only and observation coupled with ex post communication. We use a (one-shot) DG framework where the influence of social factors is manipulated via the introduction of a neutral third-party subject who 1) is incentivized independently of any of the randomly matched partners of the DG, and 2) either silently observes or observes and is required to give ex post written feedback to the giver.

The observation-only treatment can be related to several contributions on the effects of observation in experiments in economics and cognitive psychology. The seminal work of Hoffman et al. (1994) on dictator and ultimatum, testing the anonymity hypothesis by using a double-blind design, suggests that "other-regarding preferences may have an overwhelming social, what-do-other-know component" so that fairness may not be one's own preference but a derivative of the judgment of others (Hoffman et al. 1994, p. 371). Some recent work argues that selfish concerns such as guilt aversion (Charness and Dufwenberg 2006, Battigalli and Dufwenberg 2006) and self-image maintenance through self-signaling (Bodner and Prelec 2003) or self-deception (Dana et al. 2006 and 2007), can help explain seemingly altruistic behavior. 
Other theoretical contributions on social or interdependent preferences explore the suggestion that altruistic behavior can be promoted by reducing social distance ${ }^{3}$ (Hoffman et al. 1996). This literature offers several means to manipulate social distance: by making potential victims of selfishness more identifiable (cf. Schelling 1968 on the 'identifiable victim effect') through the use of photographs (Burnham 2003), by contrasting varying kinds (one-way/both ways, silent/non silent) of identification (Bohnet and Frey 2001a et 2001b), by using tacit visual or auditing clues (Haley and Fessler 2005, Bateson et al. 2006, Nettle et al. 2013) or simulating an audience effect by varying the probability of nature to play (Andreoni and Bernheim 2009).

Another strand in the related literature addresses the role of third-party informal punishment, via social approval or disapproval, for guiding behavior. Although indirectly linked to the literature on the disciplinary effect of third-party punishment in games (Fehr and Fischbacher 2004), our experimental setting departs company from it since it involves 1) informal and non pecuniary punishment, and 2) communication (at least anticipated). From this standpoint, it is more in line with the economic and psychology literature which has established that informal sanctions such as communication, permitting the expression of disapproval, can favor prosocial behaviors. For instance, Ellingsen and Johannesson (2008) provide a one-shot dictator experiment in which they compare a feedback treatment - i.e. a treatment where an anonymous verbal written message is sent by the recipient to the proposer after the pass, with a no feedback treatment, and show that anticipated rewards induce altruistic behavior. Xiao and Houser (2009) find similar results although there are more restrictions in their experimental design on the amount to pass (e.g. the divider cannot take more than $90 \%$ ) and on the content of the feedback written message. In a DG, Andreoni and Rao (2011) show that

\footnotetext{
${ }^{3}$ Social distance need to be distinguished from anonymity. Hoffman et al. (1996, p. 654) propose that social distance means a "sense of coupling between dictator and his or her counterpart." In contrast, anonymity of subjects circumvents that experimenters and/other participants find something out about the subject's decision. Koch and Normann (2008) try to disentangle the effect of regard for others from the effect of regard by others.
} 
when the receiver can speak the dictator is more generous compared to the case when only the dictator speaks. Xiao and Houser (2005) find complementary results in ultimatum games. They show that ex-post verbal written feedback messages by receivers significantly decrease the likelihood of rejecting unfair results. This suggests that verbal written communication is an expression of disapproval, which can be a non-costly substitute for monetary punishment. In the same vein, Xiao (2012) shows that in a one-shot anonymous interaction, compared with the case when the behavior is simply observed by the audience, individuals are more likely to act on what they believe the other thinks they should do (a proxy for social approval), and therefore are more reluctant to violate social norms when they have to provide the audience with justification for their decisions. The explanation provided by the author is that justification makes social norms more salient to the subjects than observation by the audience only. Finally, Charness and Dufwenberg (2010) find limited support for lying aversion and guilt aversion ${ }^{4}$.

In order to test the respective role of observation and social disapproval, we provide a framework that permits us to disentangle those two effects and to clarify their underlying motivations. To our knowledge, this is the first study to isolate the impact of observation with ex post feedback from the impact of observation-only. Moreover, it is the only contribution to deal with feedback communication from a third-party ${ }^{5}$. The paper is organized as follows. In section 2 we present the experimental design and procedures. Section 3 provides the results, which are discussed in section 4 . The paper concludes in section 5.

\section{Experimental design and procedures}

\footnotetext{
${ }^{4}$ They add to Charness and Dufwenberg (2006) a 'bare promises' treatment where the second player, before the game, can send a message to the first, either 'I promise to choose Roll' (playing the die) or a blank message. ${ }_{5}^{5}$ In contrast to Ellingsen and Johannesson (2008), we avoid a possible reciprocal effect on the receiver's feedback just because the third party is not directly concerned by the dictator's donation.
} 
In order to avoid both reputational effects due to repeated games and conditional reciprocity (i.e. reciprocal motivations based on future material payoffs), we conduct a one-shot anonymous DG experiment with and without ex post communication from a third-party which we call the observer. Regarding the role of observation-only, the motivation for our design is to test whether the introduction of a neutral observer randomly chosen among the subjects, has any effect in addition to the hypothetical effect of observation by the experimenter (see Levitt and List, 2007 on the scrutiny effect). A DG was chosen in preference to the more popular ultimatum game in order to avoid confounding altruism with risk aversion or false beliefs. Feedback from a non incentivized third-party is chosen over feedback by the recipient in order to avoid outcome-oriented punishment.

Ex-post communication takes the form of an anonymous, closed-form ${ }^{6}$ written message consisting of a list of 7 possible messages to be sent to the dictator by the third-party (the observer), ranked from 1 to 7 according to the degree of (dis)approval of the dictator's donation expressed by the observer. 'bastardo' (1) (bastard in Italian) is very harsh while 'bravissimo' (7), meaning 'this is very nice of you', is the kindest message. The item 'nessuno commento', or no comment, has the value 0 and corresponds to cases where the third-party chooses not to send any feedback. We experienced only 8 cases of no feedback. The screen seen by subjects appears as follows:

\section{[Screen 1 - around here]}

We ran three 'between' treatments in order to distinguish between the observation effect and the social disapproval effect. The first treatment (C) is a standard DG (control treatment). The second treatment $(\mathrm{O})$ is a $\mathrm{DG}$ with an observer informed about the allocator's donation (observation-only treatment). The third treatment (F) allows the observer to send written

\footnotetext{
${ }^{6} \mathrm{We}$ chose closed-form messages in particular because we wanted to create a proxy for the evaluation intensity of observers (see below). In order to reduce the dimensional problem, we selected messages whose intervals were dimensionally similar to 1 ECU. The value of 'bravissimo' is comparable to 7 ECU.
} 
feedback to the dictator (observation with feedback treatment). In the F treatment, the dictator is asked also how much he/she would keep were he/she to have the opportunity to play again. That is, the allocators are informed about the content of the feedback message from the observer attached to their group (e.g., in the screen below 'taccagno' means 'stingy') and then decide how much of their total endowment they would expend if they had the opportunity to replay. The response to this question provides some information that allows us to evaluate what we call 'ex post feedback effects' (see below).

\section{[screen 2 - around here]}

In order to test for the existence of a socialization effect ${ }^{7}$, we ran two variants of each treatment with different subjects. We hypothesized that the order in which subjects are randomly matched in pairs (for the control treatment) or groups of three (for treatments $\mathrm{O}$ and F) and attributed a role, might matter. The intuition is that grouping subjects first might decrease the social distance, and therefore affect the behavior of the allocators. We ran variants of each treatments in which subjects first were randomly matched in pairs or groups of three, and then attributed a role (proposer, recipient or possibly observer); and vice versa, that is subjects were first attributed a role and then matched into pairs or groups of three. We labeled these experiments $\mathrm{C} 1, \mathrm{O} 1$, and $\mathrm{F} 1$ respectively for the first variant, and $\mathrm{C} 2, \mathrm{O} 2$, and F2 for the second variant. (See instructions in appendix A.)

The experiment was conducted in October 2011 at the "Centro Sperimentale A Roma Est" (CESARE) on one of the campus locations of the LUISS Guido Carli University in

\footnotetext{
${ }^{7}$ The idea that grouping subjects in a DG might influence donations by dictators was introduced by Cason and Mui (1997). They compared an individual DG where the dictator decides to transfer an amount of $y$ to the recipient, with a team DG where two subjects dictate a donation of $2 y$ to be transferred. The results showed that there was group polarization in the latter context and the data indicated that team choices tended to be dominated by the more other-regarding member. However, other studies of DGs show contrasting results, i.e., an egoistic shift (Luhan et al. 2009), or no significant difference between single and group decisions (Franzen and Pointner 2014).
} 
Rome. The subjects were recruited by e-mail using ORSEE (Online Recruitment System for Economic Experiments, devised by Ben Greiner at the University of New South Wales in 1994). They were randomly allocated among the six treatments and we ran 18 sessions (6 each for the control, observation-only, and observation with feedback treatments). A total of 528 subjects participated in the experiment yielding 198 pairs or trios of observations (66 pairs of observations for the control treatments, 66 trios of observations for the observationonly treatments, and 66 trios of observations for the observation with feedback treatments). We also obtained 66 observations ${ }^{8}$ linked to the observation with feedback treatments that correspond to the post-play intentions of donations of allocators after receiving feedback from the observer.

Subjects in pairs or groups of three were anonymous to one another, and the decision of one subject was observable only by the receiver and the observer of his or her specific group of three but not by the other subjects. The instructions (translated from Italian) of the treatments $\mathrm{C} 1, \mathrm{O} 1$ and F2 are given in appendix A (remember that treatments indexed by 1 differ from those indexed by 2 only in relation to the order in which subjects were matched into pairs or groups of three and attributed the roles of proposer, recipient, or observer). At the end of the experiment, participants were asked to complete an anonymous questionnaire (professional status, discipline, age, gender). Finally, subjects were called one by one by the experimenter in order to be paid privately before leaving the lab.

The amount of the show-up was 3 ECU (Experimental Currency Unit), and the endowment of allocators 6 ECU. The observer was given a fixed amount of 6 ECU. The final gains were calculated in euros at a conversion rate of 1 ECU equals 1 euro. The minimum and

\footnotetext{
${ }^{8}$ These observations do not correspond to specific treatments but are linked to the observation with feedback treatment.
} 
maximum gains were respectively 3 euros and 9 euros. The average time of the experiments was 15 minutes.

\section{Results}

Dictators pass an average 1.98 for all treatments taken together $(33 \%$ of the dictators' endowment). In treatment $C$, the mean is 1.78 with a standard deviation (SD) equal to 1.38 , in treatment $\mathrm{O}$ it is $1.78(\mathrm{SD}=1.45)$ and in treatment $\mathrm{F}$ it is $2.37(\mathrm{SD}=1.65)$. Intentions of allocations by dictator after receiving the feedback message from the observer (F') amounts to $2.22(\mathrm{SD}=1.89)$ (see figure 1). The donations go from $29.7 \%$ of the endowment in control and silent observation, to $39.5 \%$ in the treatment with feedback, i.e., that is, donations increase by $33.1 \%$ from the two first treatments to the feedback treatment.

\section{[Figure 1-around here]}

Table 1 presents the gifts as percentages for the different treatments. Descriptive statistics are provided in appendix B.

[Table 1 - around here]

A Mann-Whitney test shows that there is no significant socialization effect. Recall that we defined this effect in relation to the order in which subjects were matched into groups of two or three and attributed roles. The absence of a significant socialization effect therefore, means that the order of the sequence of grouping and attributing roles does not modify the behavior of allocators substantially ${ }^{9}$. However, the Mann-Whitney test reveals that, if there is

\footnotetext{
${ }^{9}$ One possible explanation for the absence of a socialization effect might be that the random procedure we use to form groups in the experiment is 'very fast', not self-involving and does not seem to catch the subject's attention. More precisely, subjects are passive (they hear and read on the computer that they are going to be
} 
a significant difference between the amounts given by the proposers in treatments $\mathrm{F}$ and $\mathrm{O}$, this difference is not significant when we compare treatments $\mathrm{C}$ and $\mathrm{O}$ (see appendix $\mathrm{C}$ ). Those results are corroborated by the t-tests (see appendix C).

Since there is no significant socialization effect, data are aggregated over treatments $\mathrm{O} 1$ and $\mathrm{O} 2$, over $\mathrm{C} 1$ and $\mathrm{C} 2$, as well as over $\mathrm{F} 1$ and $\mathrm{F} 2$, to give treatments $\mathrm{C}, \mathrm{O}$ and $\mathrm{F}$ respectively. All the remaining statistics are derived from these aggregated treatments.

Interestingly, as Figure 2 illustrates, the percentages of donations in treatment $\mathrm{F}$ show a different distribution from those in treatments $\mathrm{O}$ and $\mathrm{C}$. That is, the percentages of donations under the 50:50 norm (i.e., when donations are strictly less than 3 or up to 2) are systematically lower in the $\mathrm{F}$ treatment than in the $\mathrm{C}$ and $\mathrm{O}$ treatments, while the percentages of donations over the 50:50 norm (i.e., when donations are strictly more than 3 or 4 and over) are systematically higher in the $\mathrm{F}$ treatment than in the $\mathrm{C}$ and $\mathrm{O}$ treatments ${ }^{10}$. An unusual result is that the percentage of subjects giving more than half of their endowment is high $(9 \%$ for treatment $\mathrm{C}$ and $18 \%$ for treatment $\mathrm{F}$ ). This result is difficult to explain. As for treatment $\mathrm{F}$, concerning those choices the messages received have an average value of 4.6. Moreover the correlation between the value of the messages received and the amount of money the proposers would have sent if they would have to play again equals 0.52 , although the correlation between the value of the messages and the amount sent during the game is -0.39 and the correlation between the amount sent during the game and the amount of money the proposers would have sent if they would have to play again is -0.28 . Accordingly a possible explanation is that people giving more than half of their endowment want, ex ante to test the fairness of the received message and because it is not the case they consequently reduce the

matched with one or two other subjects) and have not the time to realize (due to the speed of the flow information they are subjected to) that they have been grouped.

\footnotetext{
${ }^{10} 42 \%$ of the offers are equal at least to 3 in the observation with feedback treatment $(\mathrm{F})$ while they respectively
} reach $35 \%$ and $32 \%$ in the control $(\mathrm{C})$ and observation-only $(\mathrm{O})$ treatments. 
amount they would have given if they would have played another time. This explanation is however only a rough one and we have to admit that facts are sometimes rebel."

\section{[Figure 2-around here]}

For the observation with feedback treatment $(\mathrm{F})$, the mean of the amount that the proposer would have retained had he/she the opportunity to replay, is significantly higher (3.77) than the amount he/she effectively retained during the game (3.22). As for the message, only 36.36 percent of the messages sent were 'soft' (i.e., ranked from 4 up to 7).

As hinted in footnote 6 , we constructed a proxy variable in order to capture the intensity of evaluation of observers, defined as the difference between the degree of (dis)approval of the message sent by the observer (scaled from 1 to 7 ) and the effective amount of the donation (scaled from 0 to 6). Therefore, the intensity of evaluation of observers thus defined can take values from -5 (a seemingly excessive level of disapproval) to 7 (a seemingly excessive level of approval) (see appendix D). Following this logic, we consider that the value of a 'balanced' or 'objective' intensity of evaluation corresponds to1. The percentages of the different values taken by the intensity of evaluation are shown in figure 3 .

\section{[Figure 3 - around here]}

The student $t$-test ${ }^{11}$ shows that the mean of the distribution of the evaluation intensities (EI) is significant and equals $1^{12}$. This means that the evaluations by observers are balanced, i.e., the content of the feedback messages is close to the 'objective' one.

\footnotetext{
Te ${ }^{11}$ We used the Skewness-Kurtosis test to control for whether the distribution of intensities of evaluation is normal (Prob> chi2 $=.81)$.

${ }^{12}$ The student t-test gives: $\operatorname{Pr}(|\mathrm{T}|>|\mathrm{t}|)=0.019$ confidence interval: $[-.3587919, .8739434]$.
} 
The amount the proposer would have given, had he/she had the opportunity to play again (moneygiven2) and the amount that he/she effectively gave during the game (moneygiven 1$)$ are significantly different $(\operatorname{Pr}(|\mathrm{T}>| \mathrm{t} \mid)=0.0230)$

We run a Tobit regression (to account for left-censored dependent variable) of the amount the proposer would have given had he/she had the opportunity to play again (moneygiven2) on an interaction variable (the amount effectively given (moneygiven1) times the message), and we obtain a significant coefficient (see appendix E) ${ }^{13}$.

This means that the interaction between the feedbacks combined with the amounts the proposer gave during the game, impact on his (or her) virtual choices. Figure 4 illustrates the proposers' percentages as a function of the amount they would have given if they had the opportunity to play again, and the percentages of the various degrees of disapproval of the messages the proposers received. It shows that if the messages received are soft (from 4 to 6 ), the amount of money the proposers would have given had they had the opportunity to play again is low. If the messages are hard (from 1 to 3 ) the opposite holds: the amount of money the proposers would have given if they had had the opportunity to play again is high. Thus there is a discontinuity between messages 3 and 4 .

\section{[Figure 4-around here]}

This result is interesting and rather intuitive although it should be taken with caution since it relates to cost-free intentions which could be suspected of hypocrisy. However, this result suggests that the feedback has an ex post effect since proposers intend to give more if they receive a harsh message. This result needs to be mitigated. Figure 4 shows that dictators give more if the message is strong and give less if the message is soft.

\section{Discussion}

\footnotetext{
${ }^{13}$ This idea was suggested by one of the journal reviewers.
} 
Our experiments allow discussions of five theoretical elements: the first concerns the influence of social distance on individual behavior; the second is linked to the impact of observation on behaviors; the third is due to the possible effect of anticipated sanctions on individual decisions; the fourth concerns the evaluation intensity of the message; and the fifth refers to the possible ex post effect of a sanction.

In relation to the first issue, we argued in the introduction that altruistic behavior may be promoted by decreasing social distance, as suggested by Hoffman et al. (1996). Our results do not seem to corroborate this hypothesis since we found no differences in terms of dictators' decisions of gift if they are first matched with others and then ascribed the role of dictator or vice versa. The apparent absence of any socialization effect may be explained by a limited attention effect. If we assume that people pay attention to information conditional on its salience, our design could be criticized for giving insufficient salience to the difference in the order of the sequence presented above. This explanation could be complemented by another one. The degree of social distance is not a $0-1$ variable. In our experiment, the difference in social distance between the two versions of a given treatment appears very small. Thus, it is not surprising that such a small perturbation of social distance has no discernible effect on the amount retained.

In relation to the second issue, we also argue in the introduction that social factors such as observation, underpin social interactions so that would-be altruistic behavior may be the efficient response to the perceived situation. The results of our experiments do not support this claim since we found no significant effect of observation-only. But the absence of significance in the differences between the means of donations in treatments $\mathrm{C}$ and $\mathrm{O}$ may be due to the fact that we ran one-shot experiments. However, it corroborates the idea developed by Levitt and List (2007) that the presence of an experimenter impacts on the subjects' behavior. The presence of a silent observer replicates the presence of an experimenter, and 
therefore we should not expect any additional effect of observation by a third-party. Another interpretation might be that at least some of the allocators have some internalized social norms which induce them to transfer an amount significantly different from zero. This may explain why the presence of an observer does not have a significant impact on donations. Moreover, since subjects have no information concerning the status of the observer, it is impossible for them to infer his/her opinion or his/her preferences in terms of fairness for instance. Taking account of this uncertainty might explain why observation-only is not sufficient to have an impact on behavior.

From this standpoint, and with reference to the third theoretical element listed above, introducing the possibility - which is common knowledge - of a feedback removes the uncertainty and makes the role of the observer explicit or more salient, and therefore effective. This suggests that in our experiment, observation by others matters only if it is complemented by the likelihood of disapproval. This is in line with findings in cognitive psychology that perception can be even more powerful than 'reality' insofar as people use cues or heuristics to evaluate the likelihood that their actions are observable, and possibly disapproved. The existence of feedback therefore is a deciding factor in order for the proposers to know particulars about the third party (or to infer how this third-party thinks they are or should be), not directly concerned by the proposer's decision of donation as is the case in Ellingsen and Johannesson (2008). In other words, the anticipated feedback is a means of engineering altruism (see Burnham, 2003). The fact that proposers consequently adjust their behavior should come as no surprise. The feedback effect is economically relevant since it indicates that individuals are sensitive to anticipated possible sanctions. This suggests that feedbacks are non-costly substitutes for effective pecuniary sanctions.

Fourth, the results obtained with the proxy variable for the intensity of evaluation of observers plead for an interpretation related to reciprocity. Feedbacks are essentially 
'balanced', i.e., they are consistent with the assumption that the degree of approval is proportional to the generosity of the proposer, so that observers reciprocate proposers' donations 'fairly'.

Fifth, the fact that the degree of disapproval of messages has an impact on the amount the dictator would have given had he/she had the opportunity to replay, is interesting due to the positive relationships between the two ${ }^{14}$. In other words, the softer the message (from level 4 to level 7), the less the amount the dictator would have given if he had played one more time. Conversely, the harsher the message (from leve1 1 to level 3), the higher would be this amount. This result supports an interpretation of the feedback acting as a slightly complex disciplinary device.

\section{Conclusion}

This contribution which complements Ellingsen and Johannesson (2008) by introducing a third-party feedback, could be extended by new experiments: where the proposer plays a real (as compared to a virtual) second game after receiving feedback, which would corroborate our results concerning the amount retained by the proposer after the feedback has been received; or where a treatment is compared with the feedback from the recipient (as in Ellingsen and Johannesson, 2008) and a treatment with feedback from a third party (our own contribution).

\section{Acknowledgments}

We offer warm thanks to Jean Beuve, Anne Corcos, Werner Güth, Nicolas Jacquemet, Agnès Labrousse, Marie-Claire Villeval, and Erte Xiao and participants to the PPE seminar at George Mason University, the PPP seminar at University Paris 1, and the ASFEE meeting in La Martinique for helpful suggestions and comments. We thank the University LUISS Guido Carli for allowing us to run the experiments at CESARE (Centro di Economia Sperimentale A Roma Est). We also thank Daniela di Cagno and Francesco Farina for helping us to find

\footnotetext{
${ }^{14}$ We stress again that this interpretation should be taken with care because of the lack of monetary incentives linked to this part of the game.
} 
volunteers from LUISS students, to run the experiments. Finally, we thank Andrea Lombardo who wrote the program for the experiments using Z-tree software (Fischbacher, 2007). This research was funded by the ANR (Agence Nationale de la Recherche).

\section{References}

Andreoni, J. \& Bernheim, B.D. (2009). Social image and the 50-50 norm: A theoretical and experimental analysis of audience effect, Econometrica, 77, 1607-1636.

Andreoni, J. \& Rao, J.M. (2011). The power of asking: How communication affects selfishness, empathy, and altruism, Journal of Public Economics, 95, 513-520.

Bateson, M., Nettle, D. \& Roberts, G. (2006). Cues of being watched enhance cooperation in a real-world setting, Biology Letters, 2, 412-414.

Battigalli. P.D. \& Dufwenberg, M. (2007). Guilt in games, American Economic Review, 97, 170-176.

Becker, Gary S. (1996). Spouses and Beggars: Love and Sympathy. In G. Becker (Ed.), Accounting for Tastes, Cambridge, MA., Harvard University Press: 231-7.

Bénabou, R. \& Tirole, J. (2003).Intrinsic and extrinsic motivation, The Review of Economic Studies, 70, 489-520.

Bodner, R. \& Prelec, D. (2003).The diagnostic value of actions in a self-signaling model. In I. Brocas \& J. Carillo (Eds), The psychology of economic decisions, vol. Rationality and Wellbeing, Oxford: Oxford University Press.

Bohnet, I. \& Frey, B. (1999a).The sound of silence in prisoner's dilemma and dictator games, Journal of Economic Behavior \& Organization, 38, 43-57.

Bohnet, I. \& Frey, B. (1999b). Social distance and other-regarding behavior in dictator games: Comment, American Economic Review, 89, 335-339.

Bolton, G., Katok, E. \& Zwick, R. (1998). Dictator game giving: Rules of fairness versus acts of kindness, International Journal of Game Theory, 27, 269-299.

Burnham, T. (2003). Engineering altruism: A theoretical and experimental investigation of anonymity and gift giving, Journal of Economic Behavior \& Organization, 50, 133-144.

Camerer, C. F. (2003). Behavioral Game Theory: Experiments in Strategic Interaction.

Princeton: Princeton University Press.

Cason, T., Mui, V-L. (1997). A laboratory study of group polarisation in the team dictator game, The Economic Journal, 107, 1465-1483. 
Charness, G. \& Dufwenberg, M. (2006). Promises \& partnership, Econometrica,74, $1579-1601$

Charness, G. \& Dufwenberg, M. (2010). Bare promises: An experiment, Economics Letters, $107,281-283$.

Cooley, C. (1902). Human nature and the social order. New York: Scribner.

Crawford, V. (1998). A survey of experiments on communication via cheap talk, Journal of Economic Theory, 78, 286-298.

Dana, J., Cain, D. \& Dawes, R. (2006).What you don't know won't hurt me: Costly (but quiet) exit in dictator games, Organizational Behavior and Human Decision Processes, 100, 193-201.

Dana, J., Weber, R.A. \& Kuang J.X. (2007). Exploiting moral wiggle room: Experiments demonstrating an illusory preference for fairness, Economic Theory, 33, 67-80.

Ellingsen, T. \& Johannesson, M. (2005). Sunk costs and fairness in incomplete information bargaining, Games and Economic Behavior, 50, 155-177.

Ellingsen, T. \& Johannesson, M. (2008). Anticipated verbal feedbacks induce altruistic behavior, Evolution and Human Behavior, 29, 100-105.

Elster, Jon. (1999). Alchemies of the Mind: Rationality and the Emotions. New York, Cambridge University Press.

Fehr, E. \& Fischbacher, U. (2004).Third-party punishment and social norms, Evolution and Human Behavior, 25, 63-87.

Festré, A. \& Garrouste, P. (2012). What can experimental economics can teach us about social interactions? An institutional behavioral perspective, GREDEG Working Paper http://hp.gredeg.cnrs.fr/Pierre_Garrouste/Social_Interactions_Experimental_Economics.pdf.

Fischbacher, U. (2007). z-Tree: Zurich toolbox for ready-made economic experiments, Experimental Economics, 10, 171-178.

Franzen, A. \& Pointner, S. (2014). Giving according to preferences: Decision-making in the group dictator game, Soziale Welt, 65, 139-152.

Frohlich, N., Oppenheimer, J. \& Moore, J. (2001). Some doubts about measuring self-interest using dictator experiments: the costs of anonymity, Journal of Economic Behavior \& Organization, 46, 271-290.

Hoffman, E., McCabe, K., Sachat, K.\& Smith, V. (1994).Preferences, property rights, and anonymity in bargaining games, Games and Economic Behavior,7, 346-380.

Hoffman, E., McCabe, K. \& Smith, V. (1996). Social distance and other-regarding behavior in dictator games, American Economic Review, 86, 653-660. 
Kagel, J. H. \& Roth, A.E., Ed. (1995). Handbook of Experimental Economics. Princeton, NJ: Princeton University Press.

Koch, A.K. \& Normann, H-T. (2008). Giving in Dictator Games: Regard for Others or Regard by Others? Southern Economic Journal, 75, 223-231.

Levitt, S. D. \& List, J.A. (2007). What do laboratory experiments tell us about the real world? Journal of Economic Perspectives, 21, 153-175.

Luhan, W.J., et al. (2009). Group Polarization in the Team Dictator Game Reconsidered, Experimental Economics, 12, 26-41.

Masclet, D., Noussair, C., Tucker, S. \& Villeval, M-C. (2003). Monetary and non monetary punishment in the voluntary contribution mechanism, American Economic Review, 9, 366-380.

Nettle, D., Harper, Z., Kidson, A., Stone, R., Penton-Voak, I.S. \& Bateson, M. (2013). The watching eyes effect in the Dictator Game: it's not how much you give, it's being seen to give something, Evolution and Human Behavior, 34, 35-40.

Schelling, T. C. (1968). The life you save may be your own. In S. Chase (Ed.), Problems in Public Expenditure Analysis, Washington DC: The Brookings Institute.

Smith, A. [1759] (1976). Theory of moral sentiments. Edited by D.D. Raphael and A.L. Macfie, Oxford: Oxford Clarendon Press.

Tracy, J.L., Robins, R.W. \& Tangney, J.P. (Eds). The self-conscious emotions: theory and research. New York: Guilford Press, 2007.

Xiao, E. \& Houser, D. (2005).Emotion expression in human punishment behavior, Proceedings of the National Academy of Sciences, 102, 7398-7401.

Xiao, E. \& Houser, D. (2009), “Avoiding the sharp tongue: Anticipated written messages promote fair economic exchange”, Journal of Economic Psychology, 30(3), 393-404.

Xiao, E. (2012). Justification and Cooperation, Working Paper, University Carnegie Mellon, http://www.ewi-ssl.pitt.edu/econ/files/seminars/111027_sem891_Erte\%20Xiao.pdf. 


\section{Appendix A}

Instructions are translated from Italian, the language in which they were delivered. They were posted on the subjects' screens and read out aloud by a randomly selected subject.

Instructions of treatment $\mathrm{C} 1$ [i.e., the control treatment where groups are formed first and then roles are attributed using random procedures]

Welcome. You have agreed to participate to an experiment at the end of which you will receive at least a show-up fee of 3 euro. You may get more than this depending on your performance during the experiment. The total amount gained will be given to you at the end of the experiment. At the end of the experiment, before being paid you will be asked to complete an anonymous questionnaire (level of studies, gender, etc.).

\section{Determining the pairs}

During the experiment you will be matched randomly in groups of two persons. You will not know the identity of the other member of your pair, either during or after the experiment.

\section{Determining roles.}

You will be randomly assigned to the role of proposer (A) or receiver (B). Each proposer has an amount of 6 euro and has the possibility to transfer part of this amount to the receiver with whom he/she is matched. (For example, if A decides to transfer 2 euro to B, he or she types the amount in euro that he or she has decided to keep, namely, 4 euro).

Instructions for treatment $\mathrm{O1}$ [i.e., the treatment with observation alone where first groups are formed and then roles are attributed using random procedures] 
Welcome. You have agreed to participate in an experiment at the end of which you will receive a show-up fee of 3 euro. You may earn more depending on your performance during the experiment. The total amount of your gain will be given to you at the end of the experiment. At the end of the experiment, before being paid, you will be asked to complete an anonymous questionnaire (level of studies, gender, etc.).

\section{Determining the groups of three}

During the experiment you will be matched randomly in groups of three persons. You will not know the identity of the members of your group either during or after the experiment.

\section{Determining roles.}

You will be randomly assigned the role of proposer (A), receiver (B), or observer (C). Each proposer has an amount of 6 euro and the possibility to transfer part of this amount to the receiver with whom he/she is matched. $\mathrm{C}$ receives a fixed amount of 3 euro in addition to the show-up fee. (For example, if A decides to transfer 2 euro to B, he/she types in the amount in euro he or she has decided to keep, namely, 4 euro). The observer of his or her group is immediately notified of the amount.

\section{Instructions for treatment F2 [i.e., the treatment with observation and feedback where roles are attributed and then the groups formed using random procedures]}

Welcome. You have agreed to participate in an experiment at the end of which you will receive a show-up fee of 3 euro. You may earn more depending on your performance during the experiment. The total amount of your gains will be given to you at the end of the experiment. At the end of the experiment, before being paid you will be asked to complete an anonymous questionnaire (level of studies, gender, etc.).

\section{Determining roles}


During this experiment, you will be randomly assigned the role of proposer (A), receiver (B), or observer (C). You will not know the roles of the members of group to which you belong either during or after the experiment. Each proposer has an amount of 6 euro and has the possibility to transfer part of this amount to the receiver to whom he/she is matched. C knows what amount is transferred by $\mathrm{A}$ to $\mathrm{B}$, and has the possibility to send a written message to $\mathrm{A}$ to offer his/her opinion concerning the amount transferred. C receives a fixed amount of 3 euro in addition to the show-up fee.

A is then asked to decide the amount he/she would like to keep were he/she given the opportunity to replay.

\section{Determining the groups of three}

You will now be matched randomly in a group of three persons consisting of one proposer (A), one receiver (B), and one observer (C).

Each proposer (A) decides how much he/she is willing to transfer to the receiver (B) in his or her group. (For example, if A decides to transfer 2 euro to B, he/she types the amount in euro he/she has decided to keep, namely, 4 euro). The observer (C) in his or her group is immediately notified of the amount. $\mathrm{C}$ has the possibility to send a written message to A to offer his/her opinion concerning the amount transferred. C receives a fixed amount of 3 euro in addition to the show-up fee.

A is then asked to decide the amount he/she would like to keep were he/she given the opportunity to replay. 


\section{Appendix B - Descriptive statistics}

\begin{tabular}{|l|l|l|l|l|l|}
\hline Variables & observations & Mean & std. dev. & $\min$ & Max \\
\hline gift C & 66 & 1.787879 & 1.386919 & 0 & 6 \\
\hline gift O & 66 & 1.787879 & 1.45195 & 0 & 6 \\
\hline gift F & 66 & 2.378788 & 1.652645 & 0 & 6 \\
\hline gift F' & 66 & 2.227273 & 1.895707 & 0 & 6 \\
\hline
\end{tabular}

\begin{tabular}{|l|l|l|l|l|}
\hline Variables & gift C & gift O & gift F & gift F' \\
\hline gift C & 1.0000 & & & \\
\hline gift O & -.1220 & 1.0000 & & \\
\hline gift F & .0557 & -.1391 & 1.0000 & \\
\hline gift F' & .0596 & -.0716 & .3257 & 1.0000 \\
\hline
\end{tabular}

Correlations matrix

\section{Appendix C}

Significance tests

Two-sample Wilcoxon rank-sum (Mann-Whitney) test

\begin{tabular}{l|lll} 
giftC giftO & obs & rank sum & expected \\
\hline 1 & 66 & 4419 & 4389 \\
2 & 66 & 4359 & 4389 \\
\hline combined & 132 & 8778 & 8778 \\
H0: giftC $=$ giftO & & \\
$z$ & $=0.140$ & & \\
Prob $>|z|$ & $=0.8886$ & & H0 cannot be rejected
\end{tabular}

Significance of the difference between gift $\mathrm{C}$ and gift $\mathrm{O}$.

Two-sample Wilcoxon rank-sum (Mann-Whitney) test

\begin{tabular}{l|lll} 
giftO giftF & obs & rank sum & expected \\
\hline 1 & 66 & 3941 & 4389 \\
2 & 66 & 4837 & 4389 \\
\hline combined & 132 & 8778 & 8778
\end{tabular}

$\mathrm{H0}$ : giftO $=$ giftF

$$
\mathrm{z}=-2.084
$$

Prob $>|z|=0.0372 \quad$ H0 can be rejected 
Significance of the difference between gift $\mathrm{O}$ and gift $\mathrm{F}$

T-tests

ttest giftC $=$ giftO

Paired $t$ test

\begin{tabular}{llll}
\hline Variable Obs & Mean & Std. Err. Std. Dev. $\quad$ [95\% Conf. Interval]
\end{tabular}

\begin{tabular}{lllllll}
\hline giftC & 66 & 1.787879 & .1707179 & 1.386919 & 1.446932 & 2.128826
\end{tabular}

$\begin{array}{lllllll}\text { giftO } & 66 & 1.787879 & .1787227 & 1.45195 & 1.430945 & 2.144813\end{array}$

\begin{tabular}{lllllll}
\hline diff & 66 & 0 & .2617852 & 2.126753 & -.5228211 & .5228211
\end{tabular}

mean (diff) $=$ mean $($ giftC - giftO $)$

Ho: $\operatorname{mean}($ diff $)=0$

degrees of freedom $=65$

Ha: mean (diff) $<0$

Ha: mean(diff) $!=0$

Ha: mean (diff) $>0$

$\operatorname{Pr}(\mathrm{T}<\mathrm{t})=0.5000$

$\operatorname{Pr}(\mathrm{T}>\mathrm{t})=1.0000$

$\operatorname{Pr}(\mathrm{T}>\mathrm{t})=0.5000$

ttest giftO $=$ gifF

Paired t test

\begin{tabular}{llll}
\hline Variable Obs & Mean $\quad$ Std. Err. Std. Dev. $\quad$ [95\% Conf. Interval]
\end{tabular}

\begin{tabular}{lcccccc}
\hline giftO & 66 & 1.787879 & .1787227 & 1.45195 & 1.430945 & 2.144813 \\
giftF & 66 & 2.378788 & .2034265 & 1.652645 & 1.972517 & 2.785059 \\
& & & & & & \\
\hline diff & 66 & -.5909091 & .2888586 & 2.346698 & -1.1678 & -.0140186
\end{tabular}

$\overline{\text { mean }(\text { diff })=\text { mean }(\text { giftO }-\operatorname{giftF}) \quad \mathrm{t}=-2.0457}$

Ho: mean $($ diff $)=0 \quad$ degrees of freedom $=65$

Ha: mean(diff) $<0 \quad$ Ha: mean(diff) $!=0 \quad$ Ha: mean(diff) $>0$

$\operatorname{Pr}(\mathrm{T}<\mathrm{t})=0.0224 \quad \operatorname{Pr}(\mathrm{T}>\mathrm{t})=0.0448 \quad \operatorname{Pr}(\mathrm{T}>\mathrm{t})=0.9776$

ttest giftC $=$ gifF

Paired t test

\begin{tabular}{llll}
\hline Variable Obs & Mean & Std. Err. Std. Dev. $\quad$ [95\% Conf. Interval]
\end{tabular} 


\begin{tabular}{|c|c|c|c|c|c|c|}
\hline giftC & 66 & 1.787879 & .1707179 & 1.386919 & 1.446932 & 2.128826 \\
\hline giftF & 66 & 2.378788 & .2034265 & 1.652645 & 1.972517 & 2.785059 \\
\hline$\overline{\text { diff }}$ & 66 & -.5909091 & .2581784 & 2.097451 & -1.106527 & -.0752913 \\
\hline$\overline{\text { mean }}$ & $\mathrm{ff})=$ & mean(giftC & gifF) & & $t=$ & -2.2888 \\
\hline Ho: $n$ & (di & $f)=0$ & & des & ss of freed & $m=65$ \\
\hline Ha: $n$ & $\mathrm{n}(\mathrm{di}$ & f) $<0$ & Ha: mean $(d$ & fff) $!=0$ & Ha: mear & diff $)>0$ \\
\hline $\operatorname{Pr}(\mathrm{T}$ & $=0$ & 0127 & $\operatorname{Pr}(\mathrm{T}>\mathrm{t})=$ & 0.0254 & $\operatorname{Pr}(T>t)$ & 0.9873 \\
\hline
\end{tabular}

\section{Appendix D}

Generosity

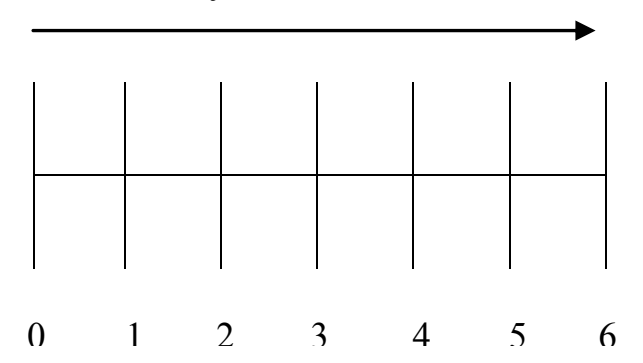

Kindness

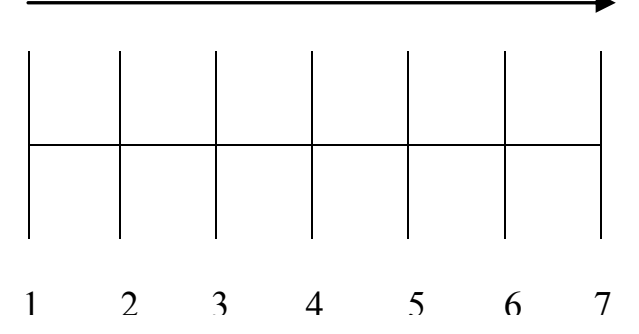

Evaluation intensity $=$ Kindness - Generosity
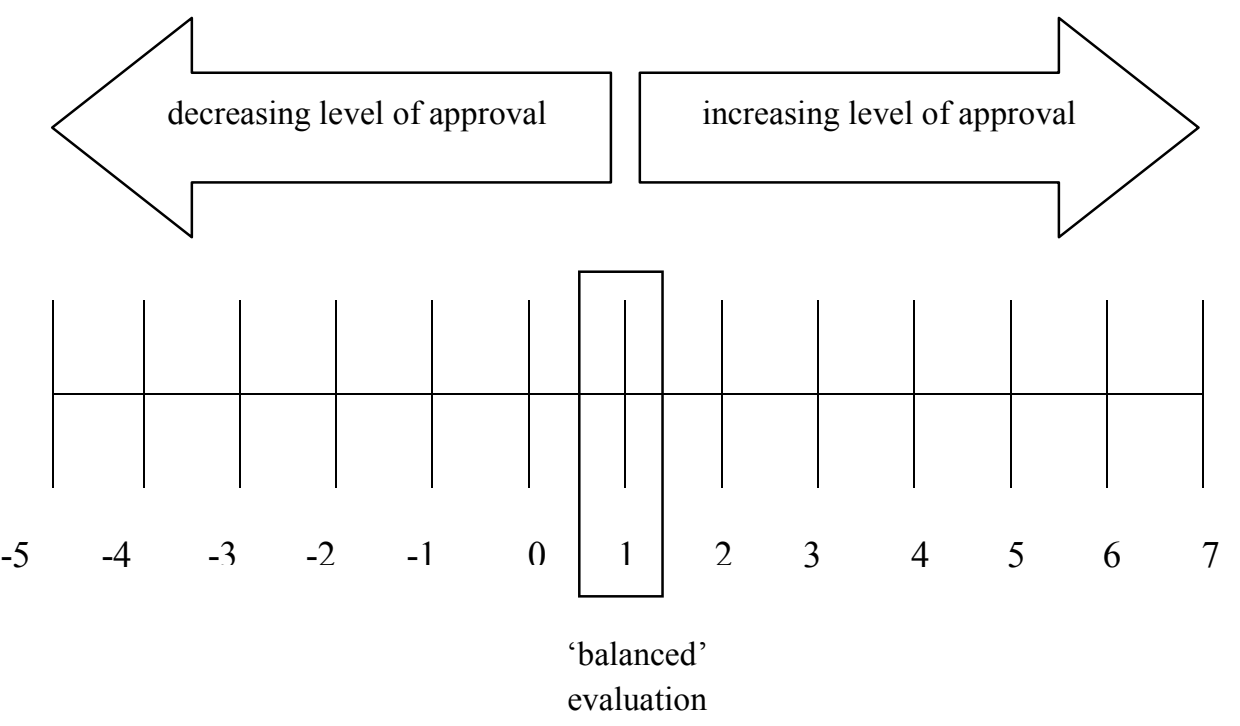
Proxy of the evaluation intensity

Appendix E

moneygiven2

\begin{tabular}{ll}
\hline model & $\begin{array}{l}0.0731^{* *} \\
\text { interact }\end{array}$ \\
& $\begin{array}{c}0.025) \\
\text { cons }\end{array}$ \\
& $(0.354)$ \\
\hline sigma & $1.618^{* * *}$ \\
cons & 58 \\
\hline $\mathrm{N}$ & \\
Standard deviations in parentheses & \\
$* \mathrm{p}<0.05 * * \mathrm{p}<0.01, * * * \mathrm{p}<0.001$ &
\end{tabular}

Tobit regression of moneygiven 2 an interaction variable (moneygiven1 time message) 


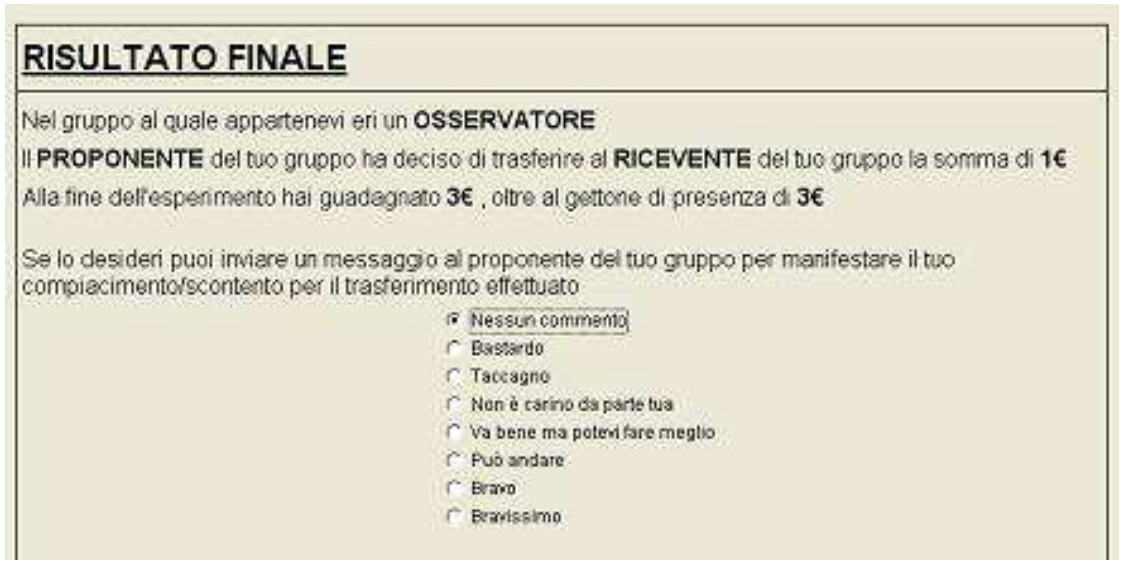

Screen 1: The feedback message stage. Translation of the list of items is as follows: Nessun commento: no comment; bastardo: bastard; taccagno : stingy; non è carino da parte tua: that's not nice of yours; vabene ma potrevi fare meglio: OK but could do better; può andare: it's OK; bravo: nice of yours; brassimimo: very nice of yours.

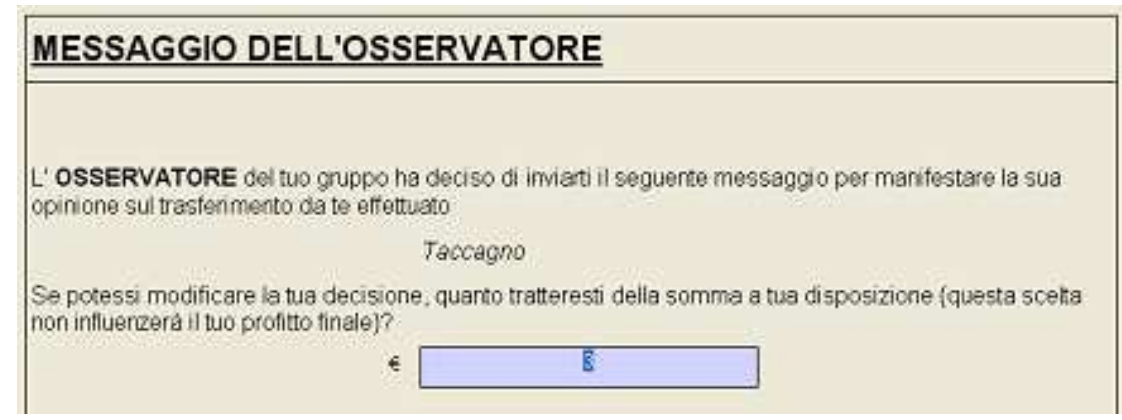

Screen 2: Dictator's intentions of donations after getting the feedback message. Translation of the screen is as follows: MESSAGE OF THE OBSERVER. The observer of your group decided to send you the following feedback message in order to give his/her opinion about how much you transferred: Stingy. If you were given the possibility to alter your decision, how much would you keep from the total amount at your disposal (this choice will not affect you final profit)? 


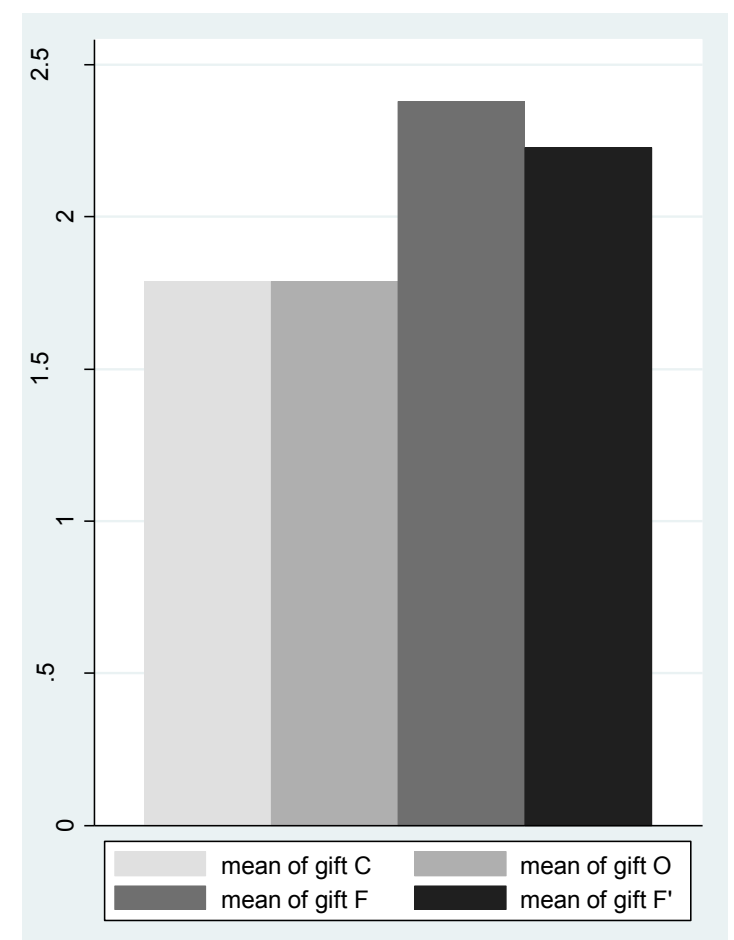

Figure 1: Means of donations in treatments $\mathrm{C}$ (gift C), $\mathrm{O}$ (Gift O), F (gift F) and intentions of donations (gift F')

\begin{tabular}{|c|c|c|c|c|c|c|}
\hline Gifts & C1 & C2 & 01 & $\mathrm{O2}$ & F1 & F2 \\
\hline 0 & 21.21 & 21.21 & 24.24 & 18.18 & 9.09 & 18.18 \\
\hline 1 & 30.30 & 24.24 & 24.24 & 30.30 & 15.15 & 9.09 \\
\hline 2 & 18.18 & 18.18 & 21.21 & 18.18 & 30.30 & 33.33 \\
\hline 3 & 24.24 & 24.24 & 24.24 & 21.21 & 21.21 & 27.27 \\
\hline 4 & 6.06 & 3.03 & 3.03 & 3.03 & 9.09 & 3.03 \\
\hline 5 & 0 & 3.03 & 0 & 9.09 & 6.06 & 3.03 \\
\hline 6 & 0 & 6.06 & 3.03 & 0 & 9.09 & 6.06 \\
\hline $\begin{array}{c}\text { Mann-Whitney test } \\
\text { Prob>lzl }\end{array}$ & \multicolumn{2}{|c|}{0.49} & \multicolumn{2}{|c|}{0.66} & \multicolumn{2}{|c|}{0.78} \\
\hline Gifts & \multicolumn{2}{|c|}{$\bar{C}$} & \multicolumn{2}{|c|}{$\bar{O}$} & \multicolumn{2}{|c|}{$\mathbf{F}$} \\
\hline 0 & \multicolumn{2}{|c|}{21.21} & \multicolumn{2}{|c|}{21.21} & \multicolumn{2}{|c|}{15.15} \\
\hline 1 & \multicolumn{2}{|c|}{27.27} & \multicolumn{2}{|c|}{27.27} & \multicolumn{2}{|c|}{12.12} \\
\hline 2 & \multicolumn{2}{|c|}{18.18} & \multicolumn{2}{|c|}{19.70} & \multicolumn{2}{|c|}{30.30} \\
\hline 3 & \multicolumn{2}{|c|}{24.24} & \multicolumn{2}{|c|}{22.73} & \multicolumn{2}{|c|}{24.24} \\
\hline 4 & \multicolumn{2}{|c|}{4.55} & \multicolumn{2}{|c|}{3.03} & \multicolumn{2}{|c|}{6.06} \\
\hline 5 & \multicolumn{2}{|c|}{1.52} & \multicolumn{2}{|c|}{4.55} & \multicolumn{2}{|c|}{4.55} \\
\hline 6 & \multicolumn{2}{|c|}{3.03} & \multicolumn{2}{|c|}{1.52} & \multicolumn{2}{|c|}{7.58} \\
\hline $\begin{array}{l}\text { Mann-Whitney test } \\
\text { Prob>lzl }\end{array}$ & \multicolumn{4}{|c|}{0.888} & & \\
\hline
\end{tabular}

Table 1: Gifts in percentages in the treatments (with the Mann-Whitney tests of significance of the differences between the gifts) 


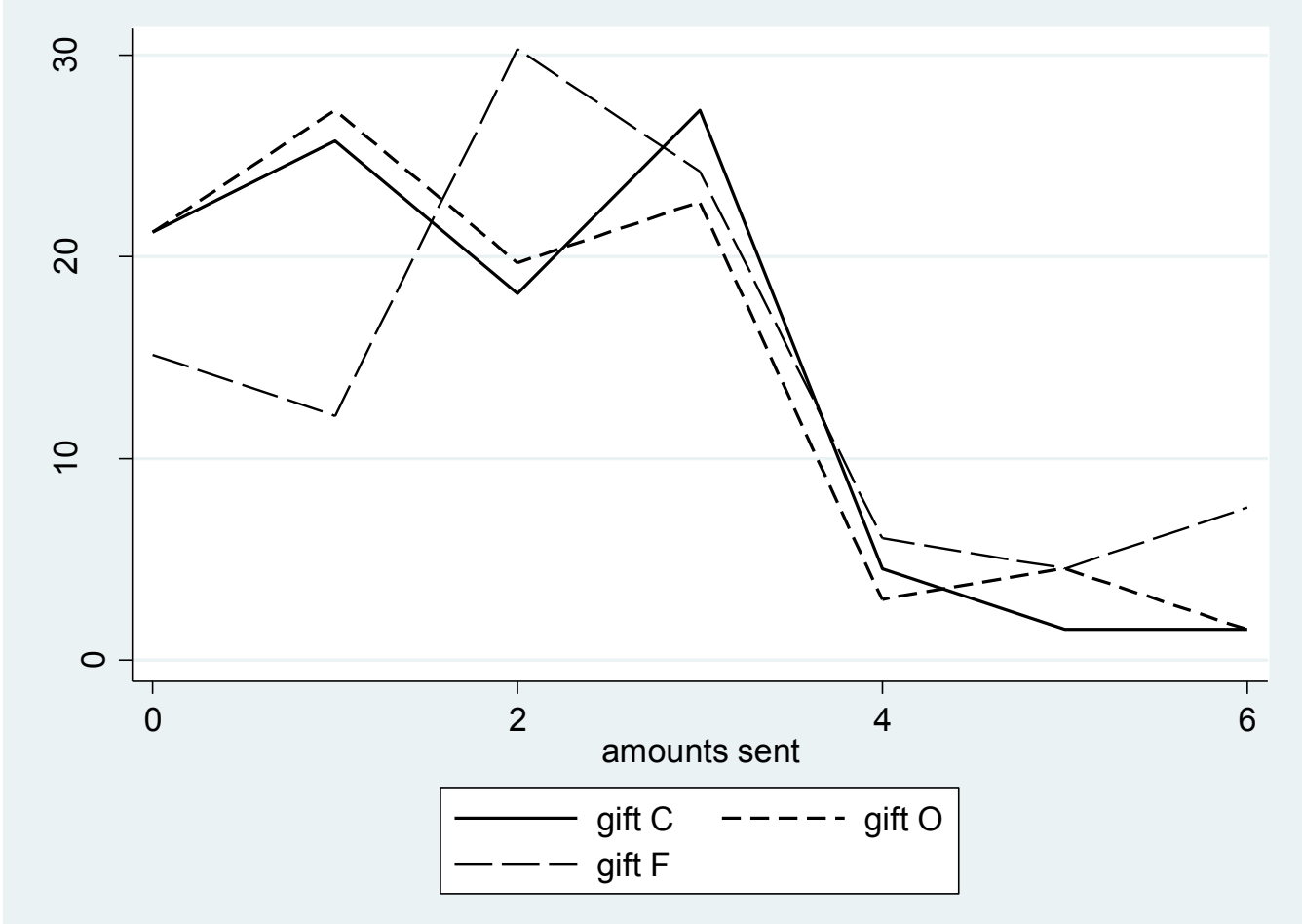

Figure 2: Percentages of donations in the control treatment (gift $\mathrm{C}$ ), in the observationonly treatment (gift $\mathrm{O}$ ) and the observation with feedback treatment (gift F)

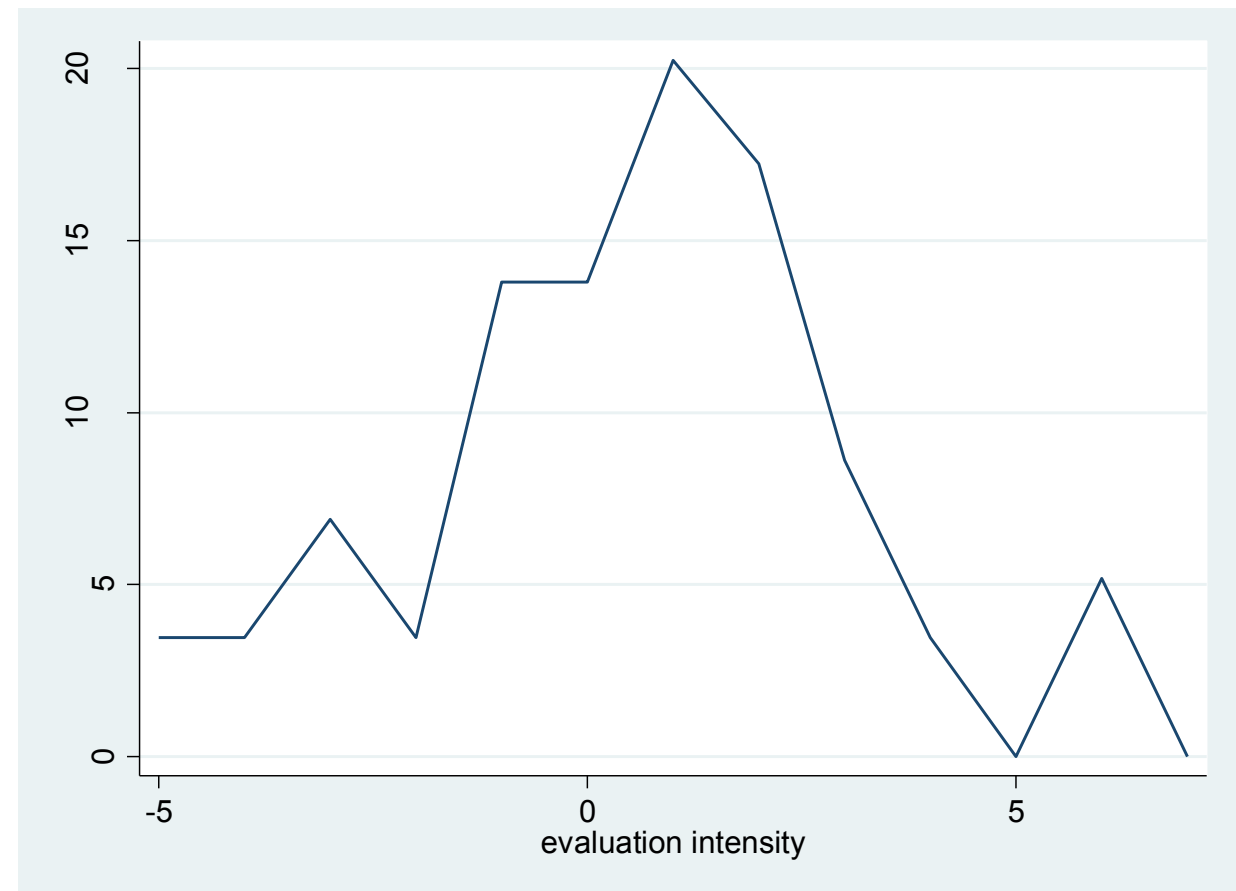


Figure 3: percentages of the evaluation intensity of observers

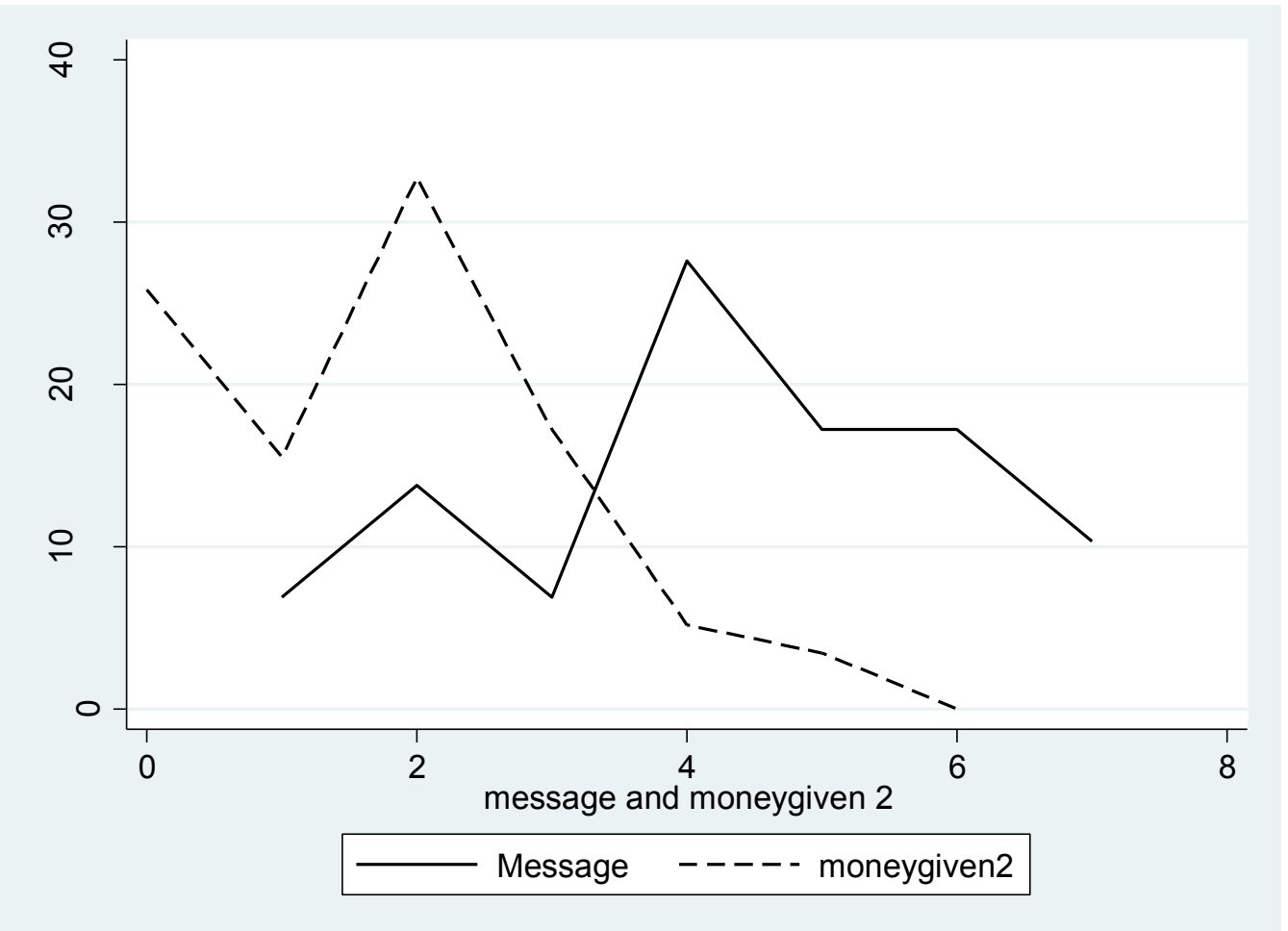

Figure 4: percentages of intentions of amount given and of the levels of (dis)approval of messages 